\title{
Challenges for nationwide vaccine delivery in African countries
}

\author{
Mario Songane $^{1}$ (D)
}

Received: 24 July 2017 / Accepted: 9 October 2017 / Published online: 19 October 2017

(C) Springer Science+Business Media, LLC 2017

\begin{abstract}
Vaccines are very effective in providing individual and community (herd) immunity against a range of diseases. In addition to protection against a range of diseases, vaccines also have social and economic benefits. However, for vaccines to be effective, routine immunization programmes must be undertaken regularly to ensure individual and community protection. Nonetheless, in many countries in Africa, vaccination coverage is low because governments struggle to deliver vaccines to the most remote areas, thus contributing to constant outbreaks of various vaccine-preventable diseases. African governments fail to deliver vaccines to a significant percentage of the target population due to many issues in key areas such as policy setting, programme management and financing, supply chain, global vaccine market, research and development of vaccines. This review gives an overview of the causes of these issues and what is currently being done to address them. This review will discuss the role of philanthropic organisations such as the Bill and Melinda Gates Foundation and global partnerships such as the global alliance for vaccines and immunizations in the development, purchase and delivery of vaccines.
\end{abstract}

Keywords Vaccine $\cdot$ Africa $\cdot$ Routine immunization $\cdot$ Supply chain · Delivery

\section{JEL Classification I18}

\section{Introduction}

Vaccines are biological preparations that confer immunity (protection) against certain pathogens. In addition to individual immunity, vaccines also reduce the spread of diseases through herd immunity (Brisson and Edmunds 2003). A clear example of the benefits of vaccines to humanity was the eradication of smallpox (declared in 1980), which killed over

Mario Songane

mario.songane@mcgill.ca

1 McGill Life Sciences Complex, McGill University, 3649 Promenade Sir-William-Osler, Montreal H3G 0B1, Canada 
300 million people in the twentieth century alone, and left millions blinded or maimed (Henderson 2011). Smallpox, like most vaccine-preventable diseases, affected mainly low and lower-middle income countries. The eradication of smallpox was a result of a decade-long World Health Organisation (WHO) led global vaccination campaign that overcame many obstacles including political instability, natural disasters, armed conflicts, bureaucratic inertia and the initial lack of funding (Henderson 2011).

Globally, routine immunization programmes against measles, polio and diphtheriatetanus-pertussis (DTP) have prevented approximately 2.5 million deaths in the first decade of the twentyfirst century (Wicker and Maltezou 2014). In the United States of America (USA), well managed routine immunization programmes has led to a decline of 90-99\% in the number of cases of diphtheria, measles, poliomyelitis, rubella, mumps, pertussis and tetanus (Roush et al. 2007; Van Panhuis et al. 2013). A similar trend has been observed in most of Europe (Wicker and Maltezou 2014).

In Africa, there have also been successful routine vaccination programmes. The measles vaccine was first introduced in the 1960s, but was largely underused and a high prevalence of measles was still observed throughout Africa until the end of the twentieth century. In 2001, the WHO, the United Nations Children's Fund (UNICEF), Centers for Disease Control and Prevention (CDC), the Pan-American Health Organization (PAHO) and the Red Cross launched a massive vaccination campaign to eradicate measles in Africa. As a result, between 2001 and 2009, measles cases decreased by 93\% (from 492,116 to 37,010) and estimated measles mortality decreased by $92 \%$ (Masresha et al. 2011, UNICEF, 2002). However, 83,625 cases in 2009 and 177,167 cases in 2013 were reported across the continent, exposing the many flaws that still exist in the delivery of vaccines in African countries (Jarosz and Naik 2015; Masresha et al. 2011).

According to the latest estimates, three million children die every year in Africa and approximately $24 \%$ of these deaths are due to vaccine-preventable diseases such as measles, tetanus, diphtheria, meningitis, yellow fever, certain types of pneumonia, and diarrhoea (Mihigo et al. 2015; Qazi et al. 2015).

In 2011 alone, diarrhoea was responsible for 700,000 deaths, while pneumonia caused 1-3 million deaths in infants (Walker et al. 2013). Deaths due to vaccine-preventable pneumonia were mainly caused by Streptococcus pneumoniae (33\%), the influenza virus (7\%) and Haemophilus influenzae type b (16\%) (Walker et al. 2013).

Rotavirus is responsible for $28 \%$ of the severe cases of diarrhoea and causes over 200,000 deaths annually around the world, mostly in developing countries, in children under 5 years of age (Tate et al. 2016; Walker et al. 2013). Despite the introduction of an effective rotavirus vaccine in 2006 (shown in clinical trials to significantly reduce episodes of severe gastroenteritis caused by rotavirus), about $70 \%$ of infants worldwide are not vaccinated and a significant number of low-income countries with a high-incidence of rotavirus are yet to introduce the vaccine (Cunliffe et al. 2012; Madhi et al. 2012; Schwartz et al. 2017).

In addition to the resulting morbidity and mortality, vaccine-preventable diseases are also a socio-economic burden because governments have to cover high treatment costs, children's academic performance and general development is severely affected, and national development and production is negatively affected due to parents missing work to take care of their children.

Research into the development and production of vaccines has increased over the last 3 decades and now there are more life-saving vaccines available to prevent a wider range of diseases. To effectively protect a population and prevent the spread of vaccine-preventable diseases, routine immunization programmes must be undertaken to ensure that all the children are fully immunized. Countries with successful routine immunization programs allocate 


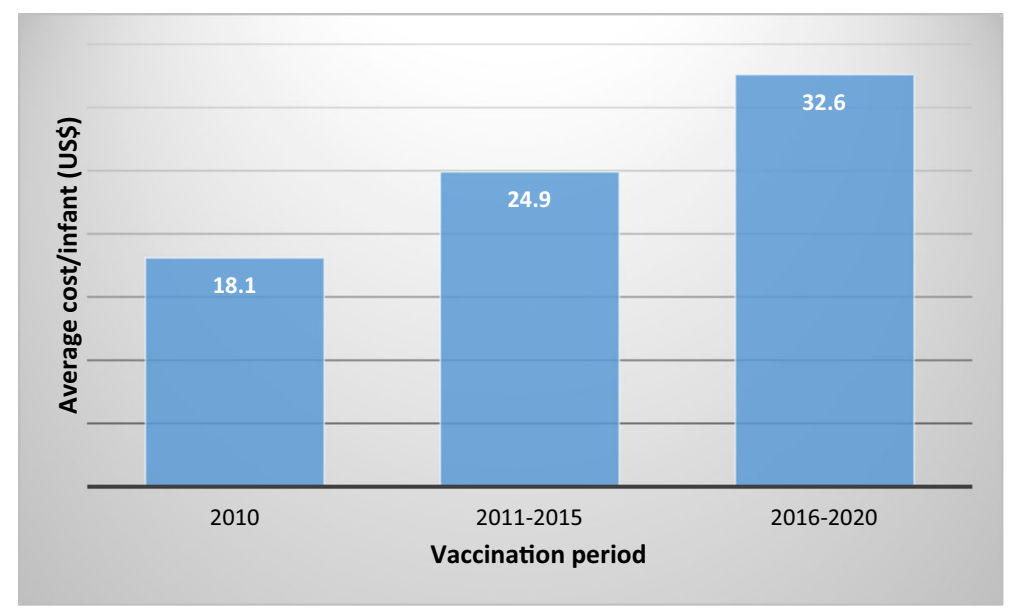

Fig. 1 Absolute values of non-vaccine costs per infant in routine immunization programmes, 2010-2020 (Lydon et al. 2014a)

adequate resources every year to ensure the availability of vaccines, the effective management of immunization programmes, and the incorporation of adequate and appropriate support services.

Routine immunization can be delivered in health facilities (fixed posts) or on-sites 10 $15 \mathrm{~km}$ from health facilities (outreach). Surveys have shown that immunization coverage is lower in rural and more isolated areas (Wesolowski et al. 2015). In these areas, children are more vulnerable to vaccine-preventable diseases because they are exposed to many other risk factors, such as limited access to clean water, malnutrition, poor healthcare facilities and bad sanitation.

In Africa, one in five children are not vaccinated due largely to the lack of or suboptimal delivery of vaccine to remote areas, the high cost of new vaccines, poor healthcare systems and badly organised routine immunization programmes (Lydon et al. 2014a). The implementation of effective routine immunization programmes in Africa therefore face many challenges which in this article are divided into four key areas: management and financing, supply chain, vaccine market, and research and development.

\section{Management and financing}

Global child mortality was reduced from 12.6 million in 1990 to 6.3 million in 2013, with improvements in routine immunization programmes in developing countries significantly contributing to this reduction (Bustreo et al. 2015). In addition, the use of vaccines against diseases such as pneumonia, diarrhoea and measles have helped prevent 2.5 million deaths annually (Tao et al. 2013).

It costs between US\$25-45 to fully immunise a child (Mihigo et al. 2016). However, these estimates exclude non-vaccine costs, which account for more than half of the total cost of immunization (Fig. 1) (Mihigo et al. 2016). Non-vaccine costs include: disease surveillance, programme management, social mobilization and advocacy, training and capacity building, human resources, vehicles and transport, cold chain equipment and overheads (Fig. 2). 


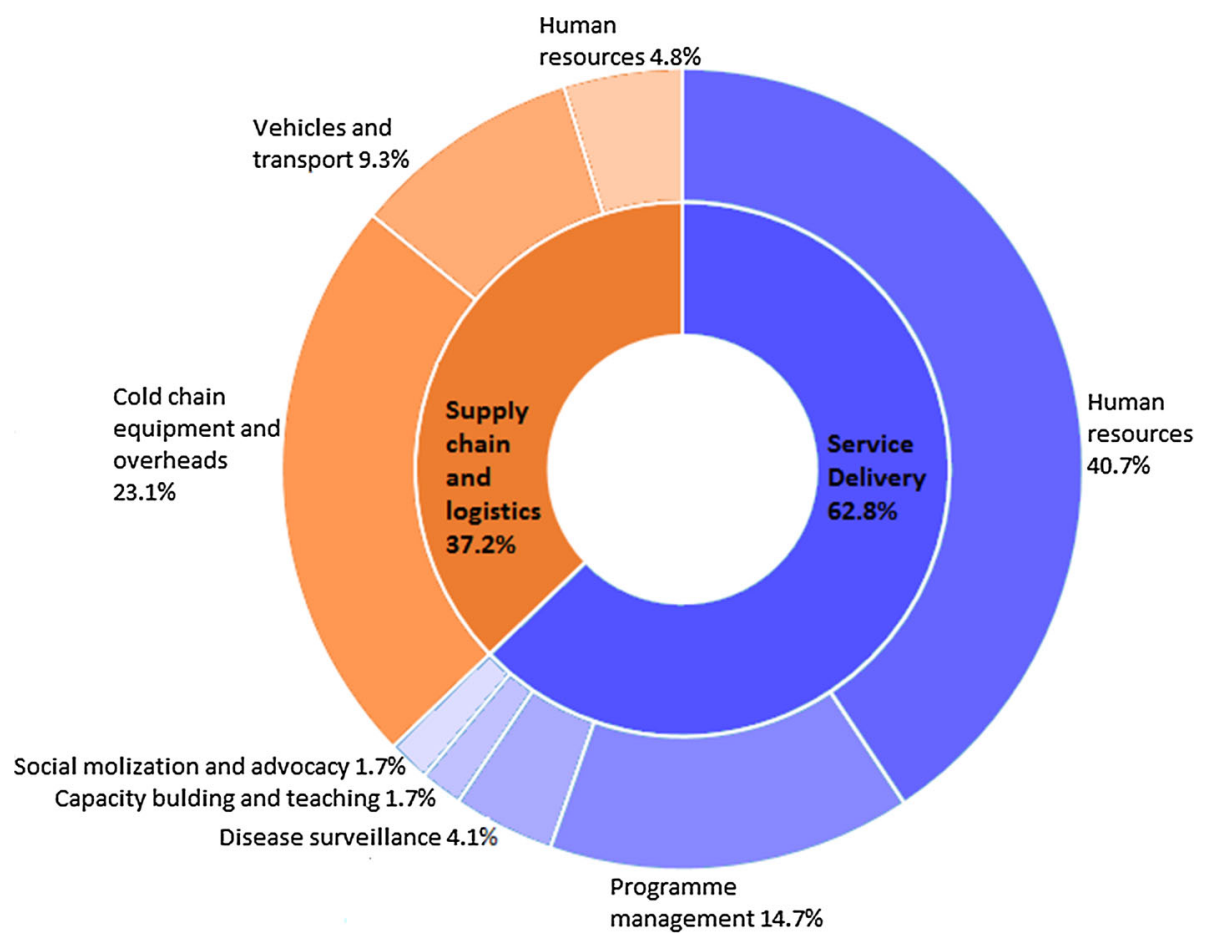

Fig. 2 Breakdown of non-vaccine expenditures during routine immunization programmes (Lydon et al. 2014a)

During the last decade, new vaccines have been introduced into routine immunization programmes in various African countries. These new vaccines pose new challenges because each one has its peculiar requirements and increases the pressure on already stretched healthcare systems. For instance, in Rwanda, it was observed that during the introduction of the Prevnar (pneumococcal), RotaTeq (rotavirus) and Gardasil (human papillomavirus-HPV) vaccines, there were significant differences in the financial costs.

For Prevnar and RotaTeq, monitoring and evaluation represented the largest share of nonvaccine costs, whereas for Gardasil, it was the service delivery (Ngabo et al. 2015). By way of comparison, delivery costs were US\$726,127 for Prevnar, US\$798,740 for RotaTeq, and US $\$ 1,096,452$ for Gardisil. These differences in service delivery were due to the fact that the target population and delivery strategies differed because pneumococcal and rotavirus vaccines are recommended for infants, whereas HPV vaccine is recommended for 9-13 year old girls. The delivering costs of Prevnar and RotaTeq were lower because they could be delivered through existing immunization programmes and the health service delivery structure. The Gardasil target population, 9-13 year old girls, on the other hand are not included in immunization programs in most developing countries and new delivery strategy and structure had to be implemented (Ngabo et al. 2015).

In addition to differences in service delivery costs, Ngabo et al. also found differences in social mobilization and training. Training costs and social mobilization for RotaTeq were cheaper because these training activities were combined with other single oral dose infant vaccines, while Gardasil required higher mobilization and training costs because it targeted an older age group and the vaccine delivery largely took place in schools (Ngabo et al. 2015). 
Furthermore, due to the fact that the HPV vaccine had to be delivered three times within 6 months, additional money needed to be spent on the greater social mobilization required, transport and per diems for the personnel involved (Ngabo et al. 2015).

African governments dedicate only a small percentage of their national budget to routine immunization programmes, despite the well-documented financial and health benefits. For instance, in Zambia, the routine immunization programme in 2014 cost US\$52.9 million, with $20 \%$ of it covered by the Global Alliance for Vaccines and Immunization (GAVI). The financial contribution of the Zambian government to the routine immunization programme corresponded to $6 \%$ of its national health expenditure, and $0.2 \%$ of its gross domestic product (GDP) (Griffiths et al. 2016). In addition, the Zambian government struggled to add US\$4.9 million to their routine immunization programme in order to introduce vaccines for pneumococcal, rotavirus, and a second dose of measles vaccine (Griffiths et al. 2016). However, compared to other African countries, Zambia allocates a much higher percentage of its GDP to routine immunization programme and depends less on the donor community to cover it ("Appendix" Table 4).

While the introduction of new and more efficient vaccines is beneficial to improving the efficiency of immunization, it is a challenging task in the often volatile economies of Africa. Zambia's annual economic growth rate declined from $7 \%$ in 2010 to $3.4 \%$ in 2015, and during this period the national currency (Kwacha) experienced large fluctuations (Hill and Cohen 2015). The declining economy, coupled with the fact that vaccine purchases are made in US dollars, made it hard for the Zambian government to allocate sufficient funds in order to add the expensive new vaccines into routine immunization programmes.

In addition to having to increase the budget to incorporate new vaccines, countries need to increase the coverage of older, but still effective vaccines that are underused, such as the vaccine against yellow fever. Yellow fever is endemic in Africa and South America, affecting those countries situated on the so-called yellow fever belt, with over 650 million vaccine doses being distributed over the past 75 years in an effort to eradicate the disease (Grobbelaar et al. 2016). The vaccine is very effective, with a single dose in most cases conferring lifelong protective immunity, and since its introduction it has led to a dramatic decrease in cases of yellow fever globally (Barrett 2016).

However, between 2010 and 2016, outbreaks of yellow fever that have killed thousands were documented in a number of African countries, including the Democratic Republic of Congo, Sudan, Chad, Senegal, Côte d'Ivoire, Uganda, Cameroon, Sierra Leone and Angola (Domingo et al. 2011; Grobbelaar et al. 2016; Wamala et al. 2012; Yuill et al. 2013). Alarmingly, 11 Chinese travellers who visited Angola were diagnosed with yellow fever upon their return to Asia, a continent that had never reported a single case of yellow fever (Barrett 2016). These disturbing reports not only highlight the urgent need to increase coverage of underused vaccines, but also the necessity to implement a global approach to effectively contain diseases like yellow fever for which effective and cheap vaccines are available.

It is estimated that between 2016 and 2020, Africa will need to invest US\$17 billion on vaccine purchases and service delivery. National governments and the donor community are expected to contribute with US $\$ 6$ billion each, with the remaining US $\$ 5$ billion needing to be raised from other sources (Mihigo et al. 2016). The financial benefits from investing US $\$ 17$ billion in routine immunization programmes are estimated to be around US\$224 billion in direct returns and savings from treating vaccine-preventable diseases (Mihigo et al. 2016). Over the last 3 decades, several initiatives have been launched to help African countries finance routine immunization programmes, as outlined bellow. 
Table 1 The stages at which the African countries receiving GAVI co-financing programme are at (GAVI 2017)

\begin{tabular}{llc}
\hline Initial self-financing (28) & Preparatory transition (8) & Accelerated transition (4) \\
\hline Benin, Burkina Faso, Burundi, The & Cameroon, Ivory Coast, & Angola, The Congo, \\
Central African Republic, Chad, & Kenya, Lesotho, \\
Comoros, The Democratic & Mauritania, Sao Tome and & \\
Republic of the Congo, Djibouti, & Principe, The Sudan, \\
Eritrea, Ethiopia, The Gambia, & Zambia & \\
Guinea, Guinea-Bissau, Liberia, & & \\
Madagascar, Malawi, Mali, & \\
Mozambique, Niger, Rwanda, & \\
Senegal, Sierra Leone, Somalia, & \\
South Sudan, Tanzania, Togo, & \\
Uganda, Zimbabwe & \\
\hline
\end{tabular}

\section{GAVI}

Towards the end of the twentieth century, investment in global immunization declined, vaccine coverage consequently stagnated, and despite the best efforts of the Expanded Programme on Immunization (EPI), over 30 million children living in developing countries were not fully immunized (GAVI 2016b). To tackle the reduction and lack of funding and expertise, the Bill and Melinda Gates Foundation committed US\$750 million for the creation of GAVI, a public-private partnership involving key United Nations (UN) agencies, governments, the pharmaceutical industry, the private sector and civil society (GAVI 2016b). The aim of the partnership is to improve childhood immunisation coverage in poor countries, accelerate access to new vaccines, provide funding to purchase new or underused vaccines, and offer technical support to 73 developing countries.

GAVI has many donors, including the Bill and Melinda Gates Foundation, which has spent over US\$2.5 billion since 1999 in GAVI projects (Foundation 2016). GAVI is the largest external funding source for vaccine purchases in Africa, helping countries introduce a range of vaccines, including those for prevention against pneumococcal disease, rotavirus and HPV (GAVI 2016b).

GAVI combines financial resources with healthcare expertise to help developing countries reach a point where they can afford to purchase vaccines without the aid of donor community. It is estimated that GAVI has helped immunize an additional 500 million children and prevent 7 million deaths (GAVI 2016b). Eligibility for GAVI funding, as well as the resulting scale and nature of the support, is determined by a country's gross national income (GNI) per capita set by the World Bank. The most recently defined low threshold is US\$1580 (Kallenberg et al. 2016).

In the initial phase of GAVI support, countries contribute with US $\$ 0.20$ per dose of any GAVI supported vaccine, and this contribution to vaccine delivery co-finance increases in accordance with increases in countries' GNI. GAVI support is divided into 4 stages: initial self-financing, preparatory transition, accelerated transition and fully self-financing (Fig. 3) (GAVI 2016b). Currently, 40 of the 73 countries being supported by GAVI are African, with the majority of these countries (28) being in the initial self-financing stage, while none have reached the fully self-financing stage (Table 1).

Under the GAVI co-financing programme, the percentage of vaccine costs covered by the government and GAVI is based on an agreed payment schedule (GAVI 2016a). However, 


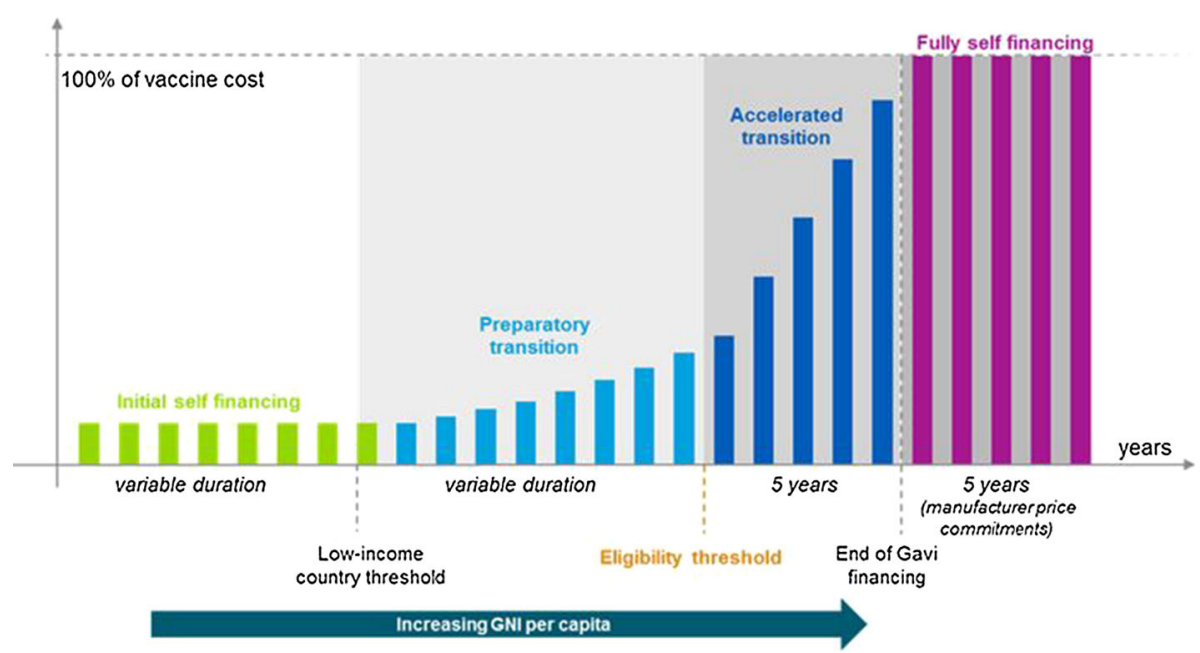

Fig. 3 The various stages of GAVI support (GAVI 2016b)

many African countries struggle to honour their obligations due to multiple reasons. In 2014, 17 countries failed to cover the full amount agreed and 5 of these countries (Djibouti, GuineaBissau, Haiti, Lesotho and South Sudan) did not contribute at all. In addition, the contribution of Guinea and Sierra Leone to vaccination were waived because of the financial and social constrains caused by the Ebola epidemic (GAVI 2015).

According to the latest GAVI reports, of all the countries taking part in this GAVI cofinancing programme, only 4 (Bhutan, Honduras, Mongolia and Sri Lanka) have achieved self-financing status and are now able to cover the costs of all GAVI-supported vaccines. In 2014, sixteen countries were upgraded to the transition to graduation stage and in 2015 fourteen countries were upgraded to this stage (GAVI 2015, 2016a).

\section{Advanced market commitment (AMC)}

High vaccine prices are a major stumbling block that prevent developing countries from expanding their routine immunization programmes. Virtually all African countries are struggling to cover the costs of vaccine purchase, including countries like Nigeria and Angola, who are among the top 5 crude oil producers in Africa (Ovadia 2014), whose governments have increased significantly the budget allocated to vaccine purchases (Fig. 4).

In an effort to lower vaccine prices, GAVI and the wider donor community in 2007 launched the Advanced Market Commitment (AMC). The first vaccine selected to test this business model was the very expensive pneumococcal conjugate vaccine. Pneumococcal disease is the leading cause of vaccine preventable diseases killing over half a million children every year (Rodgers and Klugman 2016). The aim of this pilot initiative was to accelerate the development of affordable pneumococcal vaccines that meet the needs of developing countries, promote the availability of vaccines through increase production capacity and increase vaccine purchases through pre-set prices (GAVI 2016b).

In this initiative, the donor community deposits funds with the World Bank (Table 2) which is then transferred to GAVI, according to the AMC terms and conditions, to pay vaccine manufacturers. This financial commitment, through legally-binding agreements, guarantees a certain price for the vaccines once they have been developed and also serves as an incen- 


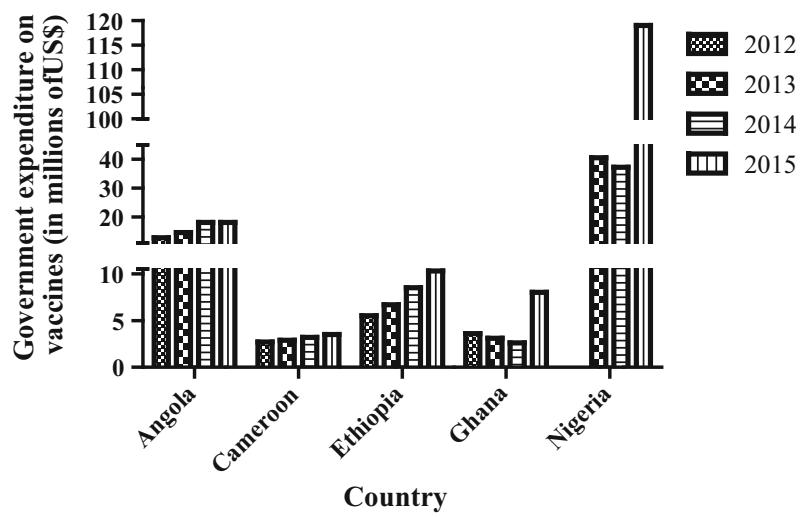

Fig. 4 Government expenditure on vaccines used in nationwide routine immunization programmes between 2012 and 2015 (Who 2016a)

Table 2 Donor commitment to the GAVI AMC program (GAVI 2016b)

\begin{tabular}{ll}
\hline Donor & Commitment (US)\$ \\
\hline Italy & 635 million \\
United Kingdom & 485 million \\
Canada & 200 million \\
The Russian Federation & 80 million \\
Norway & 50 million \\
The Bill and Melinda Gates Foundation & 50 million \\
Total & 1.5 billion
\end{tabular}

tive to manufacturers to invest in vaccine research and development, and to expand their manufacturing capacity (GAVI 2016b).

According to the agreement, participating pneumococcal vaccine manufacturers commit themselves to supply a share of the required 200 million doses per annum for 10 years at a price no higher than US\$3.50 per dose. For example, if a manufacturer commits to supply 50 million pneumococcal vaccine doses per year, it will receive US\$375 million, which corresponds to $25 \%$ of the total US $\$ 1.5$ billion AMC budget. Through this pilot initiative, two manufacturers agreed to supply pneumococcal conjugate vaccine at a reduced price, thus enabling GAVI to help immunise over 13 million children in $80 \%$ of the GAVI eligible countries (Rodgers and Klugman 2016). It is estimated that the AMC will help prevent over 7 million deaths by 2030 (Rodgers and Klugman 2016).

\section{Transition from GAVI support to self-financing}

Cost estimates of the introduction of new vaccines are vital to both GAVI and recipient countries, since these countries need to carefully plan their financial needs in order to be funded adequately. However, epidemiological data is not always accurate (particularly from remote areas) in most African countries, making it difficult for both governments and donors to correctly allocate resources. Financial figures, epidemiological data and delivery costs per dose or per child are critical for countries " policy dialogue on the sustainable financing and 
co-financing of new vaccines (Ngabo et al. 2015). In most countries the poor quality of the data from national immunization campaigns is due to three factors (Ngabo et al. 2015):

- Inappropriate reporting: inconsistent data, data not shared timely, missing data and unreliable records,

- Lack of standardised protocols at the national level: inefficient supervision, high turnover of staff, use of outdated information and practices,

- Lack of staff trained to handle data from various sources.

To tackle these problems, governments and their partners are employing a range of solutions, including on-the-job training and workshops, implementing standardised protocols for data handling and audit exercises, supportive supervision, and improved data entry practices and software (Poy et al. 2015). The Bill and Melinda Gates Foundation is one of the main supporters of these initiatives and is also helping countries develop new diagnostic tools to help health workers assess population immunity to diseases (Foundation 2016).

Thus far, as mentioned above, only Bhutan, Honduras, Mongolia, and Sri Lanka have achieved self-financing status, however, these countries are struggling to manage their routine immunization programmes independently because they also depend on other international partners to secure the other components of their programmes (Hardt et al. 2016). It is crucial that during the transition to self-financing that there is also a transfer of expertise and technology to the recipient countries so that they can effectively manage their programmes. Currently in GAVI funded programmes, while this transfer is occurring, greater effort is still required to ensure the continuous training of local staff and the acquisition of appropriate technology.

Some African countries are performing well and have successfully introduced appropriate reforms. Between 2005 and 2010, the government of Rwanda managed to reduce child mortality from 152 to 76 per 1000 livebirths, and its infant mortality from 86 to 50 per 1000 livebirths (Ngabo et al. 2015). The country successfully introduced a system of performance-based financing and community-health insurance that covers more than $90 \%$ of the population, with a minimal co-payment (Ngabo et al. 2015).

There are many major challenges in financing routine immunization programmes in Africa. As indicated above, the continent will require US $\$ 17$ billion between 2016 and 2020 to finance routine immunization programmes. These countries also need to improve the monitoring and evaluation of vaccine programmes, increase their budgets allocated to vaccine delivery, and find creative alternatives to undertake these activities more cost effectively. For example, in Rwanda, HPV vaccination was combined with the delivery of other interventions in 2015 and in 2013 HPV vaccination activities were combined with a campaign to deliver measlesrubella vaccination. Such combinations of actions lower delivery costs and also frees staff to work on other primary care activities (Ngabo et al. 2015).

\section{Supply chain}

Local governments, UNICEF and GAVI have increased vaccine purchases over the last decade to protect the population in developing countries against a range of diseases including measles, meningitis and polio. Once the vaccines reach the target countries, they depend on the local supply chain to get them from their central storage facilities to the most remote communities.

Over the last few years, new vaccines have been introduced. These vaccines often require different storage conditions (high-capacity freezers and refrigerators) and also increase the volume of product that needs to be transported, tracked and stored, thus increasing the finan- 
cial and managerial pressure to an already overwhelmed service. Costs associated with supply chains include: walk-in cold and freezer rooms at the national level, refrigerators, ice-packs, cold boxes, vaccine carriers, kerosene for absorption refrigerators, fuel, trucks and motorcycles (Lydon et al. 2014a).

Outbreaks of such vaccine-preventable diseases often occur due to gaps in the herd immunity, which are a consequence of the under-vaccination of the susceptible population. Under-vaccination is often due to vaccines not reaching the target population, stock-outs or arriving at the vaccination points damaged due to exposure to inappropriate temperatures. According to the WHO and UNICEF, most African countries don't meet the minimum standards for effective vaccine storage, distribution, handling and stock management (Lydon et al. 2015).

\section{Vaccine storage}

Governments ' inability to allocate enough funds for fuel, maintain cold chain, and sustain an integrated system to track the required products often leads to vaccine stock-outs and the inactivation of vaccines due to inadequate storage and transportation conditions. In developing countries, it is estimated that over a third of vaccine doses are wasted due to exposure to inadequate temperature, expiring in warehouses, or by misuse (Guichard et al. 2010; Parmar et al. 2010). More recent estimates, extrapolated to 2020, indicate that vaccine wastage accounts for around $8 \%$ of the total cost of immunization programmes in low and middle-income countries (Karp et al. 2015).

The biggest challenges occur in remote areas where often electricity is unavailable or unreliable, cold chain infrastructure is inadequate, and there are difficulties transporting vaccine doses to the target population living far from the health centres (Guichard et al. 2010; Parmar et al. 2010; Zaffran et al. 2013).

Most vaccines must be always kept at temperatures between 2 and $8{ }^{\circ} \mathrm{C}$, and this is one of the major challenges in the implementation of national routine immunization programs in developing countries. Over the last decades, while there has been an increase in the target population requiring vaccinations and number of vaccines to be delivered, little investment has been made in improving the supply chain (particularly cold chain equipment) and in the training of health workers involved in vaccination programmes (Kaufmann et al. 2011; Zaffran et al. 2013). A considerable percentage of the 134,000 immunization points in GAVIeligible countries have broken equipment, or fail to meet the financial demands related to the maintenance of cold chain equipment (i.e., the required purchase of gas and kerosene) (Fig. 5) (Lydon et al. 2014a).

Between 2011 and 2020, the cost to fully immunise each child will increase by $40 \%$ (Lydon et al. 2014a) due to the fact that developing countries will need to double their storage and transport capacity, and increase the number of health workers to administer six times more doses per person (Lee et al. 2013). During this period, low and lower-middle income countries will need to invest around US\$25.4 billion to cover non-vaccine costs (Lydon et al. 2014a), of which approximately $70 \%$ will be invested in human resources and the supply chain.

\section{Vaccine demand forecast and distribution}

During the twentieth century, vaccines were relatively cheap and so vaccine wastage was tolerable. However, now vaccine wastage is intolerable because there are more vaccines administered per person, the costs of development and production are higher, the population has increased, and distribution costs are greater. 


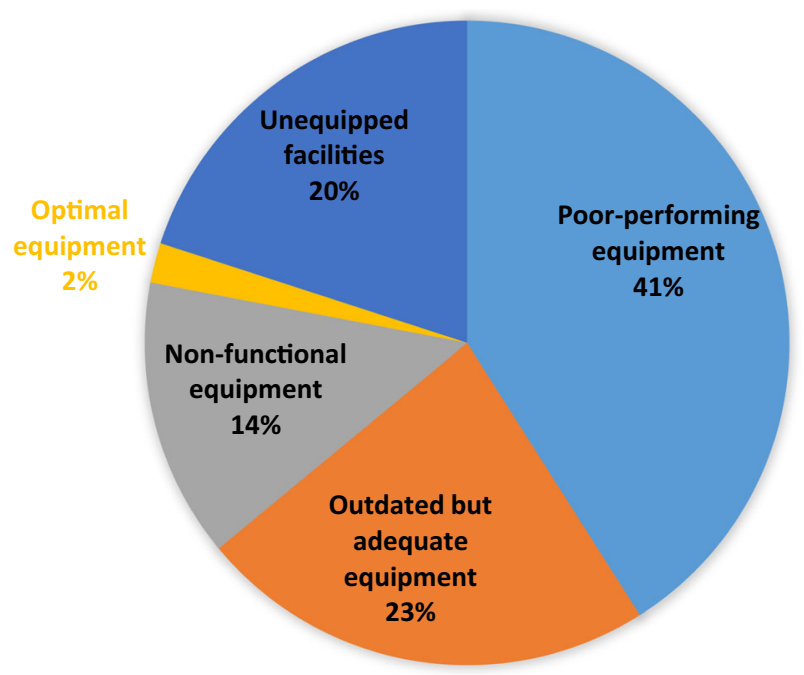

Fig. 5 Status of cold chain equipment in 134.000 immunization points in 57 GAVI-eligible countries (Lydon et al. 2014a)

The supply chain is critical for routine immunization programs and countries must ensure that they can effectively store, transport and deliver vaccines to the target population. Supply chain managers at the national and local level must forecast the quantities of each vaccine, monitor regional vaccine levels, and perform systematic preventive maintenance and repairs (Shittu et al. 2016). By accurately forecasting the needs for each region, managers can maintain lower stock levels and also reduce the hierarchical complexity of the vaccine supply chain.

In middle- and low-income countries, data generated from Demographic and Health Surveys (DHS) are used to make informed decisions on the quantity and specifications of vaccines required to be sent to each health facility (Tao et al. 2013). However, these surveys are very expensive and require an integrated system that is not available in most of these countries. Due to these issues, a considerable number of countries in Africa have failed to perform DHS every 5 years, as recommended by the WHO, thus making it difficult for programme managers to accurately forecast the specifications and quantities of vaccines to be allocated.

Alternatively, governments could reduce the complexity and financial burden of the vaccine supply chain by combining it with other health products, partnering with national rail/bus services to distribute the vaccines to health centres across the country in ice boxes, or simplifying the supply chain. In 57 GAVI-eligible countries, it was found that supply chains could be reduced from the standard 4 level to a simplified model in which vaccines could be shipped from a central location directly to immunization locations with a limited number of hubs in between (Lee et al. 2015), thus reducing costs and improving efficiency.

Where governments do not possess the financial capacity, infrastructure or expertise to handle the vaccine supply chain themselves, outsourcing components of the supply to the private sector might be a viable solution to improve the efficiency. A recent study in Cape Town (South Africa) found that outsourcing vaccine logistics to the private sector reduced delivery and inventory costs, improved adherence to temperature thresholds, reduced delivery delays, improved handling practises, and allowed greater volume flexibility (Lydon et al. 
2015). Another advantage of outsourcing the supply chain is that it would free resources, healthcare workers and storage space for other primary care services.

Another means of lowering supply chain costs is to limit the need for cold chain equipment. Certain vaccines, such as the meningococcal A conjugate vaccine, can tolerate temperatures up to $40^{\circ} \mathrm{C}$ for 4 days. Zipursky et al. (2014) assessed the benefits of using vaccines out of the cold chain during the mass immunization campaign in Benin. The team found that, because of the 4 days limit, using vaccines outside the cold chain only alleviates cold chain capacity issues for the so-called last mile (Zipursky et al. 2014).

In addition, the authors found controlled temperature chain (CTC) was strongly preferred when feasible and allowed health care workers to focus on other regular primary care services (often neglected during campaigns) (Zipursky et al. 2014). Another study in Chad, assessing the benefits of CTC during Meningococcal A conjugate vaccination, found that the costs associated with cold chain dropped by half in remote areas (Lydon et al. 2014b). However, health workers needed to be trained to handle vaccines out of the cold chain as vaccine wastage was observed in some cases where vaccines doses were kept in pockets at temperatures above $40^{\circ} \mathrm{C}$. Further research is required to consolidate information and eventually adjust the guidelines.

\section{Vaccine stock management and monitoring}

Collaborative work between GAVI, pharmaceutical companies, governments and the private sector can definitely contribute to solving a number of problems in the supply chain in Africa. A good example of such collaboration contributing to efficient supply chain management is the mVacciNation pilot programme that is ongoing in Nampula (Mozambique) in 2015 (GSK 2016). The programme involves a partnership between the pharmaceutical company GSK and the mobile services provider Vodafone, and is funded by GAVI and USAID. GSK's vaccine expertise and resources are combined with Vodafone's innovative mobile technology to help manage vaccination and supply chain.

The programme, which currently has around 35.000 children registered, started with 17 healthcare facilities, increasing to 76 by December 2015. Each facility has a smartphone with an app that allows health workers to manage various aspects of infant vaccination (register caregivers, record vaccination histories and schedule vaccination appointments through automatic SMSs), and report regularly on vaccine stock levels and refrigerator temperatures (GSK 2016). This service provides critical information that helps manage the supply chain and increase adherence to mass vaccination campaigns in remote and rural areas.

The programme is being independently evaluated by a team of researchers from the University of Cape Town and Mozambique's National Institute of Health. They will evaluate the impact of the mVacciNation on vaccine coverage, stock levels and cost effectiveness. The aim of this programme, if successful, is to expand it across Sub-Saharan Africa (GSK 2016).

The use of IT tools to monitor vaccine stock nationwide and solar-powered refrigerators have certainly helped governments manage vaccines levels in remote areas (Shittu et al. 2016). In Nigeria, effective vaccine stock monitoring has enabled more frequent supply shipments that match local needs and, when necessary, air shipments are also employed (Shittu et al. 2016).

Implementing IT tools not only helps the monitoring of vaccine stock levels, but it can also be used to develop novel models. Another collaborative project in Mozambique, involving the Ministry of Health and American scientists, employed a new model to manage supply chain which involved integrated HERMES computational modelling, supply chain structures and on the ground personnel (Lee et al. 2016). The integrated model increased vaccine availability 


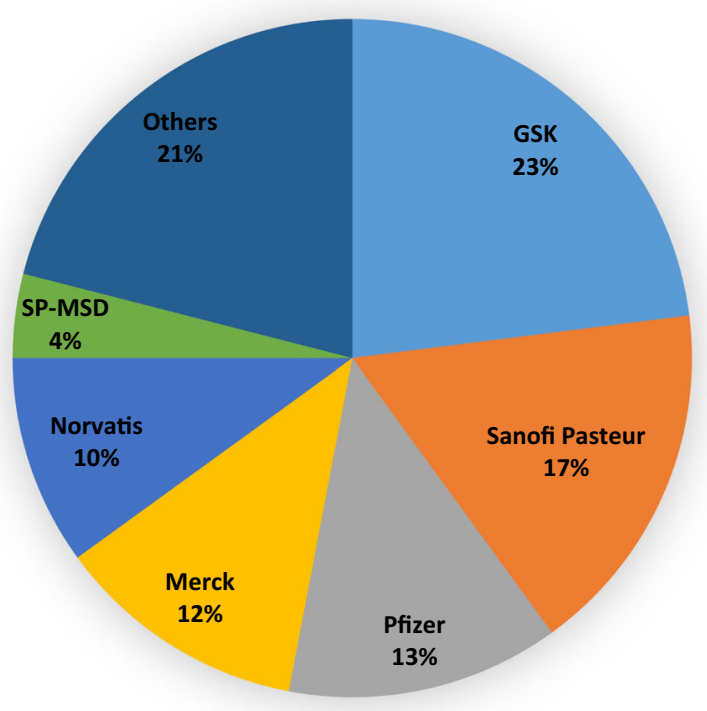

Fig. 6 The global vaccine market share (Timmons 2014)

by between 15 and 30\%, and reduced logistical costs per dose administered by approximately 40\% (Lee et al. 2016).

Vaccine supply chains in Africa are far from effective, and it is costing millions of dollars and lives every year. Over the last decade, billions of dollars have been invested to improve the supply chains and novel strategies have been employed with varying degrees of success. However, based on the information described above, a collaborative multifunctional approach would be required to increase supply chain efficiency.

\section{Vaccine market}

The global vaccine market has increased massively over the last decade, being estimated at US\$32.05 billion in 2012 and is expected to reach US $\$ 84.44$ billion by 2022 (Jadhav et al. 2014). This increase in vaccine revenue is mainly due to the introduction of highly profitable products such as the pneumococcal vaccine Prevar, which sold USD \$1.34 billion worth of doses in the first quarter of 2015, and increased purchase of vaccines by the donor community (i.e., GAVI and UNICEF) (Koons 2015; Saxenian et al. 2011). Other factors that also contributed to this increase in vaccine revenue are the recent outbreaks of vaccinepreventable diseases (i.e. influenza), the emergence of new markets, and improvements in the development and manufacturing of new vaccines.

Over the past decade, the vaccine market has been dominated by 6 multinational corporations, namely GlaxoSmithKline (GSK), SP MSD, Merck, Norvatis, Pfizer and Sanofi Pasteur (SP) (Fig. 6) (Timmons 2014). These companies grew massively over the last decade due to increased vaccine sales, GAVI's purchase of large amounts of vaccines at a significant discount (from GSK, Sanofi and Merck) and through the acquisition of smaller companies (Table 3) (Kaitin 2015; Oyston and Robinson 2012).

Despite increases in sales, the $43 \%$ price reduction of certain vaccines (pentavalent, rotavirus and pneumococcal vaccines) and the increased number of vaccine manufactur- 
Table 3 Major acquisitions in the vaccine industry between 2005 and 2015 (Kaitin 2015)

\begin{tabular}{llll}
\hline Year & Company acquired & Buyer & Cost in US\$ billion \\
\hline 2005 & Chiron & Norvatis & 5.1 \\
2005 & Corixa & GSK & 0.3 \\
2005 & ID Biomedical & GSK & 0.4 \\
2006 & Powermed & Pfizer & 0.2 \\
2007 & Coley & Pfizer & 0.7 \\
2007 & Intercell & Norvatis & 0.4 \\
2007 & MedImmune & AstraZeneca & 15.6 \\
2008 & Acambis & Sanofi Pasteur & 0.5 \\
2009 & Shantha & Sanofi Pasteur & 0.8 \\
2009 & Wyeth & Pfizer & 68 \\
2010 & VaxDesign & Sanofi Pasteur & 0.1 \\
2010 & Crucell & Johnson and Johnson & 2.6 \\
2011 & Zhejang-Tianyan & Norvatis & 0.1 \\
2014 & Baxter Vaccines & Pfizer & 0.6 \\
2015 & RedVax & Pfizer & Unknown \\
2015 & Norvatis Vaccines & GSK & 7.8 \\
\hline
\end{tabular}

ers (from 5 in 2001 to 16 in 2015), vaccine prices continue to be too high for most African countries and further price reduction measures are desperately needed to allow routine immunization programmes to reach more people (GAVI 2016a; Gilchrist and Nanni 2013).

Increased vaccine pricing transparency can promote reductions in prices and help African countries achieve their immunization targets (Hinsch et al. 2014). Clear and accurate vaccine information, along with product prices, would allow developing countries to make informed decisions on which vaccines to purchase, while aiding in the implementation of better delivery strategies (Hinsch et al. 2014). Furthermore, comparative pricing would give African countries leverage and allow them to negotiate cheaper prices (Kyle and Ridley 2007).

The major challenge for global transparent vaccine pricing is the fact that manufacturers often keep development and manufacturing costs confidential (Hinsch et al. 2014). Light et al. (2009) calculated the costs of the research and development of rotavirus vaccines and found that the pharmaceutical companies responsible for the development of these vaccines declared higher research and development costs in order to make higher profits (Light et al. 2009). These issues make it difficult for developing countries to make reliable and realistic vaccine price comparisons.

On the other hand, various authors have argued that lower vaccine prices could have negative effects on the vaccine industry. Outterson (2005) suggested that lower prices could harm profits and force companies to withdraw their least successful vaccines from the market or reduce research and development into vaccines that would be sold to developing countries (Outterson 2005).

Furthermore, new vaccines such as the rotavirus vaccines (RotaTeq and Rotarix) require heavy investment in research and development (Light et al. 2009) and, as a result, companies expect large profits from high vaccine market prices. However, if such profits cannot be guaranteed, then companies would not risk developing such vaccines. Other authors suggested low profits would mean that financially weak companies would struggle to compete with 
major multinationals, which could lead to a less competitive market (Hinsch et al. 2014). In addition, the fact that the African vaccine market value is relatively low could further deter pharmaceutical companies from investing in the development of vaccines targeting this market (Gilchrist and Nanni 2013). More research and analysis is required in different market scenarios to assess accurately the costs and benefits of transparent vaccine pricing.

GAVI expected that growing demand and increased purchases of vaccines would lead to price reductions and allow low-income countries to self-finance their immunization programmes and ensure the continuation of new vaccines. The 5-10year period predicted by GAVI for prices to decline to a level that African countries could be able to self-finance was underestimated and most GAVI-eligible countries are currently unable to sustain the introduction of new vaccines without prolonged donor support (Gilchrist and Nanni 2013). Most GAVI-eligible countries contributed only 39\% in 2008 for vaccine purchase (Lydon et al. 2008), meaning that most of the required funding came from donors.

Currently, there are numerous promising vaccines under development, increased commitment from the donor community and a higher number of WHO pre-qualified vaccines. However, there are many vaccine market related challenges preventing African countries from affording vaccines.

\section{Research and development}

Vaccine development is very risky and requires heavy investment in both infrastructure and resources. It also often happens that the investments made are not matched with high profits (Pronker et al. 2013).

Recent estimates indicate that an investment of the order of US\$500 million is required to develop simpler vaccines and over US\$1 billion to develop the most complex (Plotkin et al. 2015). Despite major investment, only $7 \%$ of vaccine candidates that reach the preclinical testing stage go on to be licensed (Pronker et al. 2013). This low rate of success is due to many factors, such as difficulties identifying vaccine targets for more complex diseases, competition with other methods of prevention and treatment, and the need to comply with tight regulatory rules that demand large scale clinical studies to prove safety and efficacy (Dimasi and Grabowski 2007; Kola and Landis 2004). In the USA for instance, it is estimated that only 1 in 5000 compounds screened is approved by the Food and Drug Administration (FDA) and it takes at least 10 years to get a vaccine candidate from inception to market release (Oyston and Robinson 2012).

Academia and NGOs contribute to the research and development of vaccines, but the vast majority of vaccines that are brought to the market are developed by pharmaceutical companies. These companies focus on market demands because they have to recoup the investment made in research and development over a decade or more. Unfortunately, the most lucrative markets are often not the ones most in need of vaccines (Oyston and Robinson 2012). A clear example is the vaccine against HIV, where the majority of market value is predicted to lie in high-income countries (i.e., Western Europe and North America), although African countries have the highest prevalence of HIV in the world and hence the higher demand (Marzetta et al. 2010).

Little research is being done on vaccines targeting neglected infectious diseases that mainly affect African countries because of their low prioritization by governments/the donor community and/or lack of interest from pharmaceutical companies due to the fact that the market is deemed to be too small (Oyston and Robinson 2012). As indicated in the ClinicalTrials.gov 
website, major pharmaceutical companies sponsor only a small percentage of clinical trials for vaccines against new infectious disease targets.

Furthermore, there is a growing need to improve some of the older vaccines, such as those used against measles and influenza, since their effectiveness has declined significantly (Belongia et al. 2015; Chen et al. 2012). However, it would require a significant investment to conduct large-scale studies to evaluate the safety and efficacy of such new vaccine versions. In addition, there is little commercial incentive to perform such studies because it would be impractical to market the reformulated vaccines at the same low prices as the current versions (Plotkin et al. 2015).

In an effort to help tackle these problems, the Bill and Melinda Gates Foundation is investing in research to improve current vaccines. Current research projects include investigating the use of adjuvants that not only strengthen the immune response, but also reduce the amount of antigen needed per dose, which could also lower the cost of vaccine production (Foundation 2016).

The World Health Organization Initiative for Vaccine Research (WHO IVR) is also contributing to the development of vaccines against neglected infectious diseases in Africa by funding innovation (including clinical trials), strengthening research capacity in target countries and promoting public-private partnerships for vaccine development (Who 2016b). In addition, pharmaceutical companies based in the BRICS countries (Brazil, Russia, India, China and South Africa) are also developing low-cost vaccines, such as the influenza vaccine that is being developed in the Russian Federation based on viral-particles, and the dengue vaccine being developed in Brazil based on technology from the United States National Institute of Health (Kaddar et al. 2014).

Another international organisation dedicated to developing and delivering vaccines to developing countries is the International Vaccine Institute (IVI). This initiative was established in 1997 by the United Nations Development Programme (UNDP) and receives funds from various sources, including the Bill and Melinda Gates Foundation, the government of the Republic of Korea (where its headquarters is based) and the Swedish International Development Cooperation Agency (IVI 2016). For example, in 2009, the killed whole-cell single dose oral cholera vaccine developed by IVI and produced by Shantha Biotechnics was licensed in India.

This vaccine has been shown to induce $65 \%$ protective efficacy and was introduced in various districts in Haiti, Ethiopia and Malawi (Charles et al. 2014; IMF 2016). In 2011, the IVI launched the Dengue Vaccine Initiative (DVI) to support the development of dengue vaccine for low- and middle-income countries, and in 2012 the IVI and SK Chemicals established a partnership to develop a new typhoid conjugate vaccine (IVI 2016).

Although these efforts contribute to the supply of low-cost vaccines, they are far from solving the problem of high costs and limited availability of vaccines for African countries. Plahte (2005) suggested the implementation of tiered pricing, in which high-income countries would pay a higher price for vaccines whereas low lower-income countries would pay lower prices (Plahte 2005). This approach would benefit all concerned because low-income countries would be able to afford vaccines, pharmaceutical companies would make large profits due to increased sales and high-income countries would purchase vaccines at a slightly lower prices.

However, this proposal may face major criticism from tax payers in high-income countries because they would feel "exploited". Other authors have suggested the removal of patents in low-income countries to promote lower prices through generic competition (Outterson and Kesselheim 2008). In this model, pharmaceutical companies owning the patents would be appropriately reimbursed for their research and development, but it is unlikely that these 
companies would agree with such deals due to the competitive market and the need to increase shareholder value.

A more achievable approach would be to create a global vaccine fund that would provide competitive grants to academic research institutions, government laboratories and small biotechnology firms to perform the early stages of vaccine research and development (Plotkin et al. 2015). The most promising candidates would go on to clinical studies sponsored by the pharmaceutical company, who would then patent the vaccine. Restricted early-stage vaccine research is the key limiting factor that hinders vaccine discovery and development, and such a fund would promote the development of a larger number of compounds to be tested.

\section{Discussion and conclusion}

Routine immunization programmes in Africa are yet to be fully effective, and most countries will struggle to meet the goals of $90 \%$ nationwide coverage and $80 \%$ coverage in every district by 2020 set by the Global Vaccine Action Plan (Who 2013). There are major global, local, financial, political and industry issues that are very complex and require creative and collaborative approaches to solve them.

An example of a very successful collaboration involving the donor community, governments and the pharmaceutical industry was the development of the meningitides A conjugate vaccine MenAfriVac, specifically designed to prevent meningitis A in Africa. The MenAfriVac was a product of the Meningitis Vaccine Project (MVP), a partnership involving the Bill and Melinda Gates Foundation (sponsor), Program for Appropriate Technology in Health (PATH) and WHO (Foundation 2016).

Following a series of MVP meetings involving WHO, PATH, representatives of African governments and the pharmaceutical industry, it was agreed that SynCo Bio Partners (Amsterdam, The Netherlands) would supply the meningococcal group A polysaccharide, the Center for Biologics Evaluation and Research of the U.S. FDA (CBER/FDA) would develop the conjugation technology, the Serum Institute of India Limited (SIIL) would manufacture the vaccine using technology transferred from CBER/FDA and The National Institute for Biological Standards and Control (United Kingdom) would conduct the quality assurance testing of the vaccine (Bishai et al. 2011; LaForce et al. 2007).

In addition, SIIL would conduct animal testing, phase I trials and, with guaranteed revenue from the 25 million doses that would be sold, build a new production facility (Bishai et al. 2011). The WHO identified the study sites, facilitated the required government approval for clinical trials, and coordinated surveillance activities for the disease (Bishai et al. 2011).

The vaccine was introduced at a price of US $\$ 0.50$ per dose in 2010 , and by late 2010 more than 19 million people had been vaccinated in Burkina Faso, Mali, and Niger (Bishai et al. 2011). The vaccination campaigns were coordinated by WHO and funded by GAVI and the Michael and Susan Dell Foundation (Bishai et al. 2011). Within 1 year of the introduction of the vaccine, a significant reduction in meningitis A cases was observed in the countries in the African meningitis belt, and one study in Burkina Faso reported that no meningitis A cases were recorded in three endemic districts 2 years after MenAfriVac vaccination (Kristiansen et al. 2014).

The MenAfriVac project showed that it is possible to research, develop and manufacture affordable new vaccines targeting African countries. As mentioned earlier in this review, the high cost of vaccines and restricted research on new vaccines against diseases that affect 
mainly developing countries are two of the biggest factors limiting the expansion of vaccine delivery in African countries.

A potential long-term alternative to ease the burden related to these two factors would be to promote the research, development and production of vaccines in African countries themselves. Taking into consideration the difficulties still faced by many countries in Africa, this should be complemented by incentives and funds for research and development, the building of manufacturing facilities, the supply of vaccine components, technology transfer, clinical trials, and surveillance.

Since the African market is deemed too small for big pharmaceutical companies, promoting vaccine development and manufacturing in African countries could be feasible because small to mid-sized companies would view it as an opportunity to increase revenue due to the fact that there would be guaranteed purchases of large quantities of vaccines and little competition from big pharmaceutical companies. In addition, the new technology transferred from partner companies could be used to develop other vaccines or medicines that could be sold to both African and, eventually, the more profitable western markets.

There are various organisations, such as the Bill and Melinda Gates Foundation that specifically donate money to address the multiple challenges in vaccine delivery; these grants could be used to build and equip research laboratories and manufacturing units in various African countries. The collaboration/partnership could be expanded to include other initiatives, like the AMC and the Global Vaccine Research Fund to provide funds for research, development, and manufacturing, as well as the establishment of a mechanism to guarantee affordable vaccine prices once they are ready to be marketed. The IVI and WHO IVR, whose mission is to promote research and development of new vaccines against infectious diseases, could provide expertise, guidance and training to local African scientists. The WHO, as they did for the MVP, could lead and coordinate such projects.

There are success stories in some countries outside Western Europe and North America, where heavy investment in the research, development and production of vaccines has been made, and who are now amongst the biggest suppliers of low-cost vaccines used in Africa. BRICS countries have invested heavily into the research, development and distribution of vaccines over the last 20 years. These countries are now major suppliers of low-cost vaccines purchased by PAHO (Pan American Health Organization), UNICEF and African governments (Kaddar et al. 2014; Roemer-Mahler 2014). The BRICS are a case in point, and they could lend their experience to a global and multifunctional initiative.

Effective immunization campaigns in Africa would contribute to eradicating the global threat of various vaccine-preventable diseases. The recent Ebola outbreak, which at one point threatened to become a global epidemic, highlighted the urgent need to develop vaccines targeting infectious diseases that affect African countries. If an effective vaccine against Ebola had been developed and sold at a price that African countries could afford, the outbreak would have been rapidly contained. In the current global economy in which people travel across countries and continents regularly, there is a growing need to intensify vaccinations in countries with high prevalence of vaccine-preventable diseases to protect their populations, and in turn to reduce the threat of global pandemics.

Ineffective routine immunization programs in African countries are a problem that financially affects Africa and the rest of the world. The case of poliomyelitis elucidates the financial benefits of eradicating diseases. The global eradication of poliomyelitis cost US\$8 billion between 1988 and 2010, but the economic benefits are estimated to be around US\$50 bil- 
lion (Oyston and Robinson 2012). It is clear that eradicating or significantly reducing the prevalence of vaccine-preventable diseases should be a global priority.

\section{Compliance with ethical standards}

Conflict of interest The author does not have conflict of interest with the contents of this article.

Ethical approval Since the article is entirely based on literature review, it did not require ethical approval.

\section{Appendix}

See Table 4.

Table 4 African governments' expenditure on routine immunization in 2014 (IMF 2015; Who 2016a)

\begin{tabular}{|c|c|c|c|c|}
\hline & $\begin{array}{l}\text { Percentage of } \\
\text { expenditure on } \\
\text { routine } \\
\text { immunization } \\
\text { funded by } \\
\text { government }(\%)\end{array}$ & $\begin{array}{l}\text { Government } \\
\text { expenditure on } \\
\text { routine } \\
\text { immunization (in } \\
\text { millions of US)\$ }\end{array}$ & $\begin{array}{l}\text { GDP (in billions } \\
\text { of US)\$ }\end{array}$ & $\begin{array}{l}\text { Government } \\
\text { expenditure on } \\
\text { routine } \\
\text { immunization as a } \\
\text { percentage of } \\
\text { GDP }(\%)\end{array}$ \\
\hline Algeria & 100 & 41.680 & & \\
\hline Angola & & & 131.407 & \\
\hline Benin & 33 & 2.114 & 9.237 & 0.023 \\
\hline Botswana & 97 & 3.521 & 16.304 & 0.022 \\
\hline Burkina Faso & 9 & 3.527 & 13.382 & 0.026 \\
\hline Burundi & 8 & 0.797 & 3.037 & 0.026 \\
\hline Cameroon & 21 & 4.947 & 32.163 & 0.015 \\
\hline Cabo Verde & 100 & & 1.975 & \\
\hline $\begin{array}{l}\text { Central African } \\
\text { Republic }\end{array}$ & 2 & 0.158 & 1.731 & 0.009 \\
\hline Chad & 54 & 2.091 & 15.841 & 0.013 \\
\hline Comoros & 8 & 0.053 & 0.722 & 0.007 \\
\hline Congo (The) & 40 & 2.557 & 14.114 & 0.018 \\
\hline Côte d'Ivoire & 25 & 6.221 & 33.963 & 0.018 \\
\hline $\begin{array}{l}\text { Democratic Republic } \\
\text { of the Congo }\end{array}$ & 5 & 3.846 & 32.665 & 0.012 \\
\hline Equatorial Guinea & 100 & 0.195 & 15.396 & 0.001 \\
\hline Eritrea & 22 & 0.462 & 3.870 & 0.012 \\
\hline Ethiopia & 33 & 36.334 & 49.857 & 0.073 \\
\hline Gabon & 98 & 1.322 & 20.675 & 0.006 \\
\hline Gambia & 35 & 0.820 & 0.918 & 0.089 \\
\hline Ghana & 19 & 5.335 & 35.475 & 0.015 \\
\hline Guinea & 7 & 3.041 & 6.770 & 0.045 \\
\hline Guinea-Bissau & & & 1.040 & \\
\hline
\end{tabular}


Table 4 continued

\begin{tabular}{|c|c|c|c|c|}
\hline & $\begin{array}{l}\text { Percentage of } \\
\text { expenditure on } \\
\text { routine } \\
\text { immunization } \\
\text { funded by } \\
\text { government }(\%)\end{array}$ & $\begin{array}{l}\text { Government } \\
\text { expenditure on } \\
\text { routine } \\
\text { immunization (in } \\
\text { millions of US)\$ }\end{array}$ & $\begin{array}{l}\text { GDP (in billions } \\
\text { of US)\$ }\end{array}$ & $\begin{array}{l}\text { Government } \\
\text { expenditure on } \\
\text { routine } \\
\text { immunization as a } \\
\text { percentage of } \\
\text { GDP }(\%)\end{array}$ \\
\hline Kenya & 14 & 5.311 & 62.722 & 0.008 \\
\hline Lesotho & 99 & 1.151 & 2.458 & 0.047 \\
\hline Liberia & 6 & 0.266 & 2.073 & 0.013 \\
\hline Madagascar & & 2.733 & 11.188 & 0.024 \\
\hline Malawi & 10 & 1.651 & 4.408 & 0.037 \\
\hline Mali & 17 & 5.482 & 12.043 & 0.046 \\
\hline Mauritania & 29 & 1.707 & & \\
\hline Mauritius & & & 12.720 & \\
\hline Mozambique & 22 & 5.429 & 16.590 & 0.033 \\
\hline Namibia & & & 11.982 & \\
\hline Niger & & & 8.290 & \\
\hline Nigeria & 24 & 49.206 & 594.257 & 0.008 \\
\hline Rwanda & 11 & 2.464 & 8.002 & 0.031 \\
\hline $\begin{array}{l}\text { Sao Tome and } \\
\text { Principe }\end{array}$ & 77 & 0.593 & 0.362 & 0.164 \\
\hline Senegal & 8 & 2.217 & 15.881 & 0.014 \\
\hline Seychelles & 97 & 0.369 & 1.473 & 0.025 \\
\hline Sierra Leone & 22 & 1.395 & 5.411 & 0.026 \\
\hline South Africa & 100 & & 341.216 & \\
\hline South Sudan & & & 11.893 & \\
\hline Swaziland & 97 & 1.836 & 3.842 & 0.048 \\
\hline Tanzania & 21 & 15.444 & 36.620 & 0.042 \\
\hline Togo & 25 & 0.920 & 4.838 & 0.019 \\
\hline Uganda & 49 & 16.151 & 26.086 & 0.062 \\
\hline Zambia & 80 & 42.3 & 21.150 & 0.2 \\
\hline Zimbabwe & 30 & 13.303 & 13.739 & 0.097 \\
\hline
\end{tabular}

\section{References}

Barrett, A. D. T. (2016). Yellow fever in Angola and beyond-The problem of vaccine supply and demand. New England Journal of Medicine, 375, 301-303.

Belongia, E. A., Sundaram, M. E., Mcclure, D. L., et al. (2015). Waning vaccine protection against influenza A (H3N2) illness in children and older adults during a single season. Vaccine, 33, 246-251.

Bishai, D. M., Champion, C., Steele, M. E., \& Thompson, L. (2011). Product development partnerships hit their stride: Lessons from developing a meningitis vaccine for Africa. Health Affairs, 30, 1058-1064.

Brisson, M., \& Edmunds, W. (2003). Economic evaluation of vaccination programs: The impact of herdimmunity. Medical Decision Making, 23, 76-82.

Bustreo, F., Okwo-Bele, J.-M., \& Kamara, L. (2015). World Health Organization perspectives on the contribution of the global alliance for vaccines and immunization on reducing child mortality. Archives of Disease in Childhood, 100, S34-S37. 
Charles, R. C., Hilaire, I. J., Mayo-Smith, L. M., et al. (2014). Immunogenicity of a killed bivalent (O1 and O139) whole cell oral cholera vaccine, Shanchol, in Haiti. PLOS Neglected Tropical Diseases, 8, e2828.

Chen, C.-J., Lee, P.-I., Hsieh, Y.-C., et al. (2012). Waning population immunity to measles in Taiwan. Vaccine, 30, 6721-6727.

Cunliffe, N. A., Witte, D., Ngwira, B. M., et al. (2012). Efficacy of human rotavirus vaccine against severe gastroenteritis in Malawian children in the first two years of life: A randomized, double-blind, placebo controlled trial. Vaccine, 30, A36-A43.

Dimasi, J. A., \& Grabowski, H. G. (2007). The cost of biopharmaceutical R\&D: Is biotech different? Managerial and Decision Economics, 28, 469-479.

Domingo, C., Yactayo, S., Agbenu, E., et al. (2011). Detection of yellow fever 17D genome in urine. Journal of Clinical Microbiology, 49, 760-762.

Foundation, G. (2016). Country programs and partnerships [Online]. http://www.gatesfoundation.org/WhatWe-Do/Global-Development/Vaccine-Delivery. Accessed November 30, 2016.

GAVI. (2015). 2014 annual progress report. http://www.gavi.org/results/gavi-progress-reports/.

GAVI. (2016a). 2015 annual progress report. http://www.gavi.org/results/gavi-progress-reports/.

GAVI. (2016b). Gavi's mission [Online]. http://www.gavi.org/about/. Accessed November 30, 2016.

GAVI. (2017). Country hub [Online]. GAVI. http://www.gavi.org/country/. Accessed September, 142017.

Gilchrist, S. A. N., \& Nanni, A. (2013). Lessons learned in shaping vaccine markets in low-income countries: A review of the vaccine market segment supported by the GAVI Alliance. Health Policy and Planning, $28,838-846$.

Griffiths, U. K., Bozzani, F. M., Chansa, C., et al. (2016). Costs of introducing pneumococcal, rotavirus and a second dose of measles vaccine into the Zambian immunisation programme: Are expansions sustainable? Vaccine, 34, 4213-4220.

Grobbelaar, A. A., Weyer, J., Moolla, N., et al. (2016). Resurgence of yellow fever in Angola, 2015-2016. Emerging Infectious Diseases, 22, 1854-1855.

GSK. (2016). The power of partnerships: Transforming vaccine coverage in Mozambique [Online]. http://www.gsk.com/en-gb/behind-the-science/how-we-do-business/the-power-of-partnershipstransforming-vaccine-coverage-in-mozambique/. Accessed November 30, 2016.

Guichard, S., Hymbaugh, K., Burkholder, B., et al. (2010). Vaccine wastage in Bangladesh. Vaccine, 28, $858-863$.

Hardt, K., Bonanni, P., King, S., et al. (2016). Vaccine strategies: Optimising outcomes. Vaccine, 34, 66916699.

Henderson, D. A. (2011). The eradication of smallpox-An overview of the past, present, and future. Vaccine, 29. Supplement, 4, D7-D9.

Hill, M., \& Cohen, M. (2015). Once feted Zambia now snubbed as power cuts worsen crisis. Bloomberg business. New York: Bloomberg.

Hinsch, M., Kaddar, M., \& Schmitt, S. (2014). Enhancing medicine price transparency through price information mechanisms. Globalization and Health, 10, 34.

IMF. (2015). World economic outlook database, 2015 [Online]. Washington, DC, United States: International Monetary Fund. https://www.imf.org/external/pubs/ft/weo/2014/02/weodata/weoselgr.aspx. Accessed September 15, 2017.

IMF. (2016). History [Online]. http://www.ivi.int/?page_id=12433. Accessed December 1, 2016.

Jadhav, S., Gautam, M., \& Gairola, S. (2014). Role of vaccine manufacturers in developing countries towards global healthcare by providing quality vaccines at affordable prices. Clinical Microbiology and Infection, 20, 37-44.

Jarosz, B., \& Naik, R. (2015). Progress stalls on vaccine-preventable diseases [Online]. Population Reference Bureau. http://www.prb.org/Publications/Articles/2015/vaccine-preventable-disease-progress. aspx. Accessed December 2, 2016.

Kaddar, M., Milstien, J., \& Schmitt, S. (2014). Impact of BRICS? Investment in vaccine development on the global vaccine market. Bulletin of the World Health Organization, 92, 436-446.

Kaitin, K. I. (2015). Vaccine products in the R\&D pipeline have more than tripled since 2005. Tufts Center for the Study of Drug Development Impact Report, 17.

Kallenberg, J., Mok, W., Newman, R., et al. (2016). Gavi's transition policy: Moving from development assistance to domestic financing of immunization programs. Health Affairs, 35, 250-258.

Karp, C. L., Lans, D., Esparza, J., et al. (2015). Evaluating the value proposition for improving vaccine thermostability to increase vaccine impact in low and middle-income countries. Vaccine, 33, 3471-3479.

Kaufmann, J. R., Miller, R., \& Cheyne, J. (2011). Vaccine supply chains need to be better funded and strengthened, or lives will be at risk. Health Affairs, 30, 1113-1121.

Kola, I., \& Landis, J. (2004). Can the pharmaceutical industry reduce attrition rates? Nature Reviews Drug Discovery, 3, 711-716. 
Koons, C. (2015). Photographer: Daniel Acker/Bloomberg Pfizer profit tops estimates as Prevnar vaccine sales rise. Bloomberg business. New York: Bloomberg.

Kristiansen, P. A., Ba, A. K., Ouédraogo, A.-S., et al. (2014). Persistent low carriage of serogroup A Neisseria meningitidis two years after mass vaccination with the meningococcal conjugate vaccine, MenAfriVac. BMC Infectious Diseases, 14, 1.

Kyle, M. K., \& Ridley, D. B. (2007). Would greater transparency and uniformity of health care prices benefit poor patients? Health Affairs, 26, 1384-1391.

Laforce, F. M., Konde, K., Viviani, S., \& Préziosi, M.-P. (2007). The meningitis vaccine project. Vaccine, 25(Supplement 1), A97-A100.

Lee, B. Y., Connor, D. L., Wateska, A. R., et al. (2015). Landscaping the structures of GAVI country vaccine supply chains and testing the effects of radical redesign. Vaccine, 33, 4451-4458.

Lee, B. Y., Haidari, L. A., Prosser, W., et al. (2016). Re-designing the Mozambique vaccine supply chain to improve access to vaccines. Vaccine, 34, 4998-5004.

Lee, L. A., Franzel, L., Atwell, J., et al. (2013). The estimated mortality impact of vaccinations forecast to be administered during 2011-2020 in 73 countries supported by the GAVI Alliance. Vaccine, 31, 2, B61-B72.

Light, D. W., Andrus, J. K., \& Warburton, R. N. (2009). Estimated research and development costs of rotavirus vaccines. Vaccine, 27, 6627-6633.

Lydon, P., Beyai, P. L., Chaudhri, I., et al. (2008). Government financing for health and specific national budget lines: The case of vaccines and immunization. Vaccine, 26, 6727-6734.

Lydon, P., Gandhi, G., Vandelaer, J., \& Okwo-Bele, J.-M. (2014a). Health system cost of delivering routine vaccination in low- and lower-middle income countries: what is needed over the next decade? Bulletin of the World Health Organization, 92, 382-384.

Lydon, P., Raubenheimer, T., Arnot-Krüger, M., \& Zaffran, M. (2015). Outsourcing vaccine logistics to the private sector: The evidence and lessons learned from the Western Cape Province in South-Africa. Vaccine, 33, 3429-3434.

Lydon, P., Zipursky, S., Tevi-Benissan, C., et al. (2014b). Economic benefits of keeping vaccines at ambient temperature during mass vaccination: the case of meningitis A vaccine in Chad. Bulletin of the World Health Organization, 92, 86-92.

Madhi, S. A., Kirsten, M., Louw, C., et al. (2012). Efficacy and immunogenicity of two or three dose rotavirusvaccine regimen in South African children over two consecutive rotavirus-seasons: A randomized, double-blind, placebo-controlled trial. Vaccine, 30, A44-A51.

Marzetta, C. A., Lee, S. S., Wrobel, S. J., et al. (2010). The potential global market size and public health value of an HIV-1 vaccine in a complex global market. Vaccine, 28, 4786-4797.

Masresha, B. G., Fall, A., Eshetu, M., et al. (2011). Measles mortality reduction and pre-elimination in the African region, 2001-2009. Journal of Infectious Diseases, 204, S198-S204.

Mihigo, R., Anya, B., \& Masresha, B. (2015). 1 in 5 children in Africa do not have access to life-saving vaccines [Online]. World Health Organisation-Africa. http://www.afro.who.int/en/media-centre/ afro-feature/item/7620-1-in-5-children-in-africa-do-not-have-access-to-life-saving-vaccines.html. Accessed December 2, 2016.

Mihigo, R. M., Okeibunor, J. C., O'malley, H., et al. (2016). Investing in life saving vaccines to guarantee life of future generations in Africa. Vaccine, 34, 5827-5832.

Ngabo, F., Levin, A., Wang, S. A., et al. (2015). A cost comparison of introducing and delivering pneumococcal, rotavirus and human papillomavirus vaccines in Rwanda. Vaccine, 33, 7357-7363.

Outterson, K. (2005). Pharmaceutical arbitrage: Balancing access and innovation in international prescription drug markets. Yale Journal of Health Policy, Law, and Ethics, 5, 193-291.

Outterson, K., \& Kesselheim, A. S. (2008). Market-based licensing for HPV vaccines in developing countries. Health Affairs, 27, 130-139.

Ovadia, J. S. (2014). Local content and natural resource governance: The cases of Angola and Nigeria. The Extractive Industries and Society, 1, 137-146.

Oyston, P., \& Robinson, K. (2012). The current challenges for vaccine development. Journal of Medical Microbiology, 61, 889-894.

Parmar, D., Baruwa, E. M., Zuber, P., \& Kone, S. (2010). Impact of wastage on single and multi-dose vaccine vials: Implications for introducing pneumococcal vaccines in developing countries. Human Vaccines, 6 , 270-278.

Plahte, J. (2005). Tiered pricing of vaccines: A win-win-win situation, not a subsidy. The Lancet Infectious Diseases, 5, 58-63.

Plotkin, S. A., Mahmoud, A. A. F., \& Farrar, J. (2015). Establishing a global vaccine-development fund. New England Journal of Medicine, 373, 297-300. 
Poy, A., Masresha, B., Shaba, K., et al. (2015). Immunization monitoring and vaccine-preventable diseases surveillance data management in the African Region. Africa Health Monitor, 1, 46-50.

Pronker, E. S., Weenen, T. C., Commandeur, H., et al. (2013). Risk in vaccine research and development quantified. PLOS ONE, 8, e57755.

Qazi, S., Aboubaker, S., Maclean, R., et al. (2015). Ending preventable child deaths from pneumonia and diarrhoea by 2025. Development of the integrated global action plan for the prevention and control of pneumonia and diarrhoea. Archives of Disease in Childhood, 100, S23-S28.

Rodgers, G. L., \& Klugman, K. P. (2016). Surveillance of the impact of pneumococcal conjugate vaccines in developing countries. Human Vaccines \& Immunotherapeutics, 12, 417-420.

Roemer-Mahler, A. (2014). The rise of companies from emerging markets in global health governance: Opportunities and challenges. Review of International Studies, 40, 897-918.

Roush, S. W., Murphy, T. V., \& Vaccine-Preventable Disease Table Working Group. (2007). Historical comparisons of morbidity and mortality for vaccine-preventable diseases in the United States. JAMA, 298, 2155-2163.

Saxenian, H., Cornejo, S., Thorien, K., et al. (2011). An analysis of how the GAVI alliance and low- and middle-income countries can share costs of new vaccines. Health Affairs, 30, 1122-1133.

Schwartz, L. M., Halloran, M. E., Rowhani-Rahbar, A., et al. (2017). Rotavirus vaccine effectiveness in low-income settings: An evaluation of the test-negative design. Vaccine, 35, 184-190.

Shittu, E., Harnly, M., Whitaker, S., \& Miller, R. (2016). Reorganizing Nigeria's vaccine supply chain reduces need for additional storage facilities, but more storage is required. Health Affairs, 35, 293-300.

Tao, W., Petzold, M., \& Forsberg, B. C. (2013). Routine vaccination coverage in low- and middle-income countries: Further arguments for accelerating support to child vaccination services. Global Health Action, 6, 20343.

Tate, J. E., Burton, A. H., Boschi-Pinto, C., et al. (2016). Global, regional, and national estimates of rotavirus mortality in children $<5$ years of age, 2000-2013. Clinical Infectious Diseases, 62, S96-S105.

Timmons, H. (2014). The pharma industry's blockbuster $\$ 29$ billion, three-way deal is all about specialization. Quartz. New York: Atlantic Media Co.

UNICEF. (2002). Five leading global health organizations announce a new initiative to save children from measles deaths in Africa as part of a global effort to reduce child mortality. https://www.unicef.org/ newsline/02prmeasles1.htm. Accessed December 14, 2016.

Van Panhuis, W. G., Grefenstette, J., Jung, S. Y., et al. (2013). Contagious diseases in the United States from 1888 to the present. New England Journal of Medicine, 369, 2152-2158.

Walker, C. L. F., Rudan, I., Liu, L., et al. (2013). Global burden of childhood pneumonia and diarrhoea. The Lancet, 381, 1405-1416.

Wamala, J. F., Malimbo, M., Okot, C. L., et al. (2012). Epidemiological and laboratory characterization of a yellow fever outbreak in northern Uganda, October 2010-January 2011. International Journal of Infectious Diseases, 16, e536-e542.

Wesolowski, A., O'meara, W. P., Tatem, A. J., et al. (2015). Quantifying the impact of accessibility on preventive healthcare in sub-Saharan Africa using mobile phone data. Epidemiology (Cambridge, Mass. ), 26, 223228.

WHO. (2013). Global vaccine action plan 2011-2020. http://www.who.int/immunization/global_vaccine_ action_plan/GVAP_doc_2011_2020/en/. Accessed December 15, 2016.

WHO. (2016a). Immunization financing indicators. http://www.who.int/immunization/programmes_systems/ financing/data_indicators/en/. Accessed September 4, 2017.

WHO. (2016b). Immunization, vaccines and biologicals [Online]. http://www.who.int/immunization/ research/en/. Accessed December 1, 2016.

Wicker, S., \& Maltezou, H. C. (2014). Vaccine-preventable diseases in Europe: Where do we stand? Expert Review of Vaccines, 13, 979-987.

Yuill, T. M., Woodall, J. P., \& Baekeland, S. (2013). Latest outbreak news from ProMED-mail. Yellow fever outbreak-Darfur Sudan and Chad. International Journal of Infectious Diseases, 17, e476-e478.

Zaffran, M., Vandelaer, J., Kristensen, D., et al. (2013). The imperative for stronger vaccine supply and logistics systems. Vaccine, 31, 2, B73-B80.

Zipursky, S., Djingarey, M. H., Lodjo, J.-C., et al. (2014). Benefits of using vaccines out of the cold chain: Delivering Meningitis A vaccine in a controlled temperature chain during the mass immunization campaign in Benin. Vaccine, 32, 1431-1435. 